\title{
O problema da quarta motivação no âmbito ascético
}

\author{
The problem of the fourth motivation in the ascetic ambit
}

\author{
Felipe Cardoso Martins Lima \\ Doutorando em Filosofia pela UFSC \\ Professor do Departamento de Filosofia da Universidade Federal do Acre (UFAC) \\ E-mail: felipecardosofl@ig.com.br
}

\begin{abstract}
Resumo: Pretende-se apresentar neste artigo uma análise da noção de liberdade a partir da filosofia de Schopenhauer. Objetiva-se, por um lado, comentar a ideia de uma liberdade consciente no fenômeno, na qual são enaltecidos os aspectos do conhecimento do todo da vida, e, por outro, ressaltar a presença de uma Besonnenheit der Vernunft, anunciada por Schopenhauer como um meio termo entre conhecimento intuitivo e abstrato. Propõe-se, então, debater essa noção, uma vez que, embora tal Besonnenheit der Vernunft se dê no âmbito místico, serão demonstradas algumas possibilidades interpretativas, das quais se sobressalta a impossibilidade da liberdade no âmbito fenomênico, seja na esfera negativa (asceta), seja no horizonte afirmativo (conquistador de mundos). Assim, para alcançar o objetivo fundamental desse artigo, a investigação se fundamentará nos quadros principais do pensamento schopenhaueriano, a partir da análise rigorosa das três motivações das ações humanas e, em especial, de uma quarta motivação própria do asceta, apresentada no parágrafo 48 dos suplementos.
\end{abstract}

Palavras-chave: Vontade; Liberdade; Asceta.

Abstract: It is intended to provide an analysis of the concept of freedom from the Schopenhauer's philosophy in this research. The objective is, to comment on the idea of conscious freedom in a phenomenon, in which are enhanced the aspects of the knowledge of whole of life, and another side, to emphasize the presence of a Besonnenheit der Vernunft (Clairvoyance of the reason), announced by Schopenhauer as a middle ground between intuitive and abstract knowledge. Then it proposes to discuss this notion, since, although such Besonnenheit der Vernunft is given the in the mystical ambit, will be demonstrated some interpretative possibilities, including the crucial flinches impossibility of freedom in the phenomenal context, whether in the negative sphere (ascetic), or in the affirmative horizon (conqueror of worlds). Thus, to achieve the fundamental goal of this thesis, the research will build in main frames of Schopenhauer's thought, from the rigorous analysis of the three motives of human actions and, in particular, a fourth motivation - the ascetic owns it - presented in paragraph 48 of the supplements.

Keywords: Will; Freedom; Ascetic.

Schopenhauer é herdeiro da problemática kantiana da terceira antinomia, isto é, da distinção entre caráter inteligível e de caráter empírico. Mas é na própria noção de caráter que ele mostra ao mesmo tempo seu distanciamento. Se Kant demarcou o terreno próprio do caráter inteligível e empírico, por sua vez Schopenhauer interpretaria a coisa em si como forma de manifestação da Vontade no indivíduo, conferindo a 
qualidade de imutabilidade à noção de caráter. Essa reviravolta implicará a presença da ideia de um destino implacável para cada indivíduo, uma vez que tal caráter denotará um sentido pessoal, constante e inato.

Ele observa que apesar de haver uma essência universal, a vontade individual representaria um fragmento desta e, em cada ação específica, se lançaria de acordo com os motivos mais resolutos, ou seja, de acordo com os motivos abstratos mais determinantes para a vontade. Por isso, mesmo envolvendo seu pensamento num dualismo entre o inteligível e o empírico, ele faz emergir deles a ideia de caráter como ato singular da vontade, uma vez que por esse princípio fica pressuposto como uma característica específica, um modo peculiar de ser, inalterável por toda a vida. Por fim, tal postulação intrínseca ao indivíduo representaria um determinismo do qual somente poderia se dissociar pela rara negação da Vontade de vida, isto é, mediante a aniquilação do próprio caráter no horizonte ascético.

É a causalidade que determinará o caráter empírico, pois assumiu a forma de motivação, portanto, do fenômeno em suas diversidades individuais de manifestações como atos da Vontade espraiados no tempo e no espaço sob o absoluto rigor da necessidade e dos motivos. Por sua vez, o caráter inteligível, além de ser livre, é também imutável. Diz Schopenhauer:

Foi, porém, Kant que primeiro esclareceu este ponto importante por meio de sua grande doutrina de que o caráter empírico que, como fenômeno, apresenta-se no tempo e numa multiplicidade de ações tem por fundamento o caráter inteligível que é a qualidade da coisa em si daquele fenômeno e, por isso, independe do espaço e do tempo, da multiplicidade e da mudança. Só a partir daí torna-se explicável a tão espantosamente rígida imutabilidade dos caracteres experimentada por todos ${ }^{1}$.

Mas tal separação configurará a total eliminação da liberdade no âmbito fenomênico. De fato, todos os fenômenos estão submetidos ao domínio do princípio de razão suficiente, inclusive as ações humanas, pois essas devem seguir necessariamente a determinação de um motivo e também a de um caráter. A esse respeito, Schopenhauer comenta:

\footnotetext{
${ }^{1}$ SCHOPENHAUER, A. Über die Grundlage der Moral - M/M, p. 193. 
Entende-se por necessário tudo aquilo que resulta de dada razão suficiente [...] Trata-se, porém, da ordem dos fatos que porventura tratam a necessidade da consequência como sempre absoluta quando for dada a razão suficiente. Não é somente ao concebermos uma coisa como consequência de razão determinada que reconhecemos sua necessidade; e, inversamente, apenas reconhecemos que uma coisa depende, como efeito de uma razão suficientemente conhecida, concebemo-la necessária, dado que todas as razões são necessitantes. ${ }^{2}$

Assim, admitir a liberdade equivaleria a conceber a exclusão de uma razão suficiente perfeitamente determinada. Ora, se a Vontade em si é livre, não está submetida ao domínio do princípio de razão suficiente, então pode se considerar a nãonecessidade como um de seus aspectos principais. Sendo assim, Schopenhauer é enfático ao afirmar que a liberdade tomada em sentido negativo não pode estar relacionada com as relações de causa e efeito, pois essas já pressupõem a necessidade, que, por sua vez, submete todos os fenômenos individuais: "Seja como for, o vocábulo livre significa o que não é necessário sob relação alguma, o que não depende de toda razão suficiente" (Schopenhauer, 1982, p.159).

Todavia, a necessidade de toda determinação causal tem de concordar com a essência do ser, no caso do homem, com o caráter. Todas as ações individuais sempre estarão em consonância com o próprio caráter. Eis o que defende Schopenhauer: "O homem em si não muda nunca: como agiu em um caso, tornará a agir quando iguais circunstâncias se repetirem" (Schopenhauer, 1982, p. 226). É a partir da ideia de um determinismo das ações humanas, e buscando sua compreensão, que se é levado a entender melhor a supressão da liberdade no plano fenomênico. Assim sendo, a exteriorização da liberdade no mundo empírico não se deve apenas ao aspecto contraditório, mas também a uma reconsideração da dimensão do ser. Isso se torna possível porque afirmar uma manifestação da liberdade consciente pressupõe afirmar também a existência do fenômeno excepcional da negação da Vontade de vida. Por conta dessa contradição subjacente, o indivíduo negaria o seu próprio querer, subtraindo, do mesmo modo, a afirmação do corpo.

É importante notar que se inicia um rompimento decisivo das relações de causa e efeito - sendo causa equivalente a motivo, e efeito equivalente a ato ou vontade individual. Essa supressão viabilizaria a liberdade consciente das ações, uma vez que o

\footnotetext{
${ }^{2}$ SCHOPENHAUER, A. Über die Freiheit des Willens - F/L , p. 158. 
princípio de razão deixaria de impor sua necessidade ao fenômeno. Schopenhauer adverte, então, que "o único caso no qual aquela liberdade também pode se tornar imediatamente visível no fenômeno é quando põe fim ao que aparece" (Schopenhauer, 2005, p. 508).

Entretanto, quando se analisa a figura do místico, vê-se que nela perpassa o sentimento da compaixão, uma vez que o místico representa um prolongamento dela. Isso leva a necessidade de uma revisão do viés ético para ser possível compreender a constituição de uma mística pela clareza constitutiva da consciência, isto é, do conhecimento do todo da vida.

Quando se detém no estabelecimento do fundamento da moral, mais precisamente a própria compaixão, não apenas se constata o desprendimento em relação ao $e u$, mas também a preocupação em favor do não $e u$, sucumbindo nesse processo o conhecimento abstrato, próprio da razão. Todavia, a intuição tem um papel fundamental para o fenômeno espontâneo da Mitleid, que, do mesmo modo, representaria uma etapa antecedente à renúncia definitiva do asceta.

A ética Schopenhaueriana busca suas raízes no mundo empírico e nada tem a ver com reflexões abstratas, uma vez que não corresponde a prescrição de regras de conduta, como na ética kantiana, ou ainda, no ensinamento, pois, segundo Barboza, "é tão quixotesco esperar de uma ética a formação de virtuosos, nobres e santos quanto da estética a formação de poetas, pintores e músicos” (Barboza, 2005, p. 262). Ainda assim, no que diz respeito à compaixão, Schopenhauer não estabelece apenas um fundamento empírico para a Mitleidsethik, mas um fundamento metafísico também. Esses dois "fundamentos" estão claramente diferenciados em "Sobre o fundamento da moral". O aspecto misterioso da compaixão participa do seu fundamento metafísico, o que leva o filósofo a recorrer à metáfora védica do Tat-twam-asi ou do Mahavakya, o "grande verbo".

Para melhor compreender como isso complica o campo da teorização da liberdade em Schopenhauer é necessário examinar o conceito de motivações, situadas no agir e particularizadas pelo princípio de razão. Seriam três as formas em que se apresentam as motivações humanas, não sendo apropriado considerar apenas o egoísmo, mas também a maldade e a compaixão. 
Há em suma apenas três motivações das ações humanas, e só por meio do estímulo delas é que agem todos os motivos possíveis. Elas são: a) egoísmo, que quer seu próprio bem (é ilimitado); b) maldade, que quer o mal estar alheio (chega até a mais extrema crueldade); c) compaixão, que quer o bem estar alheio (chega até a nobreza moral e a generosidade ${ }^{3}$ ).

Schopenhauer apresenta a motivação egoísta como uma das maiores expressões da afirmação da Vontade de vida, presente na Wirklichkeit (efetividade) dos fenômenos. Com relação a essa efetividade, "o querer tudo para si e nada para o outro" expressaria unicamente a natureza do egoísta. Além disso, o filósofo concebe o egoísmo como sendo a primeira motivação antimoral, motivação essa que se revela essencial, motor da diversidade das ações humanas ${ }^{4}$ e dos animais.

A partir dessas considerações, seria possível perceber certas limitações no conhecimento dos indivíduos egoístas, sobretudo em termos metafísicos, pelo fato de não reconhecerem a unidade e a identidade da Vontade em todos os seus níveis. Assim, nada obsta o egoísta de aniquilar tudo aquilo que põe resistência a seus intentos. Seus interesses estão acima das necessidades alheias e, tomando o eu como a única verdade, o egoísta conceberia a pluralidade dos fenômenos como meras representações. Dessa forma, o egoísta reconhecer-se-ia como um mero ente particularizado e totalmente distinto dos outros.

As considerações de Schopenhauer sobre o egoísmo ilimitado se baseiam no pensamento oriental budista; nessa perspectiva, a ilusão do conhecimento não se apresentaria a partir do nada, mas em função do Véu de Maia. Nesses termos, o indivíduo permaneceria distante do conhecimento da Vontade, enxergaria o mundo apenas submetido aos fenômenos. Sob a égide do Véu de Maia, a essência do mundo estaria representada no próprio $e u$ do indivíduo, uma vez que a realidade do egoísta é compreendida como sendo imediata, pois se daria por si e para si. Por conta dessa motivação, apenas seu próprio bem-estar estaria em jogo; o restante dos fenômenos se apresentaria de forma mediata para ele, por meio de suas representações. Schopenhauer entende que:

\footnotetext{
${ }^{3}$ SCHOPENHAUER, A.Über die Grundlage der Moral - M/M, p. 137.

${ }^{4}$ Eigennutz (interesse próprio). Trata-se de um egoísmo guiado pela razão, ou seja, próprio do homem. 
O egoísmo, de acordo com sua natureza, é sem limites: o homem quer conservar incondicionalmente sua existência, a quer incondicionalmente livre da dor à qual também pertence toda penúria e privação, quer a maior soma possível de bem estar, quer todo o gozo (...). Tudo que se opõe ao esforço do seu egoísmo excita sua má vontade, ira e ódio; procurará aniquilá-lo como a seu inimigo (...) "tudo para mim e nada para o outro" é sua palavra de ordem. (...) Se fosse dado, pois, a um indivíduo escolher entre a sua própria aniquilação e a do mundo, nem preciso dizer para onde a maioria se inclinaria ${ }^{5}$.

É importante notar que agora não estão em jogo apenas as motivações egoístas cujo objetivo é o bem-estar de si próprio -, mas também a malevolência, que diferente do egoísmo, visa fundamentalmente o mal-estar alheio. De acordo com Schopenhauer, a malevolência - segunda motivação antimoral - é proveniente de uma colisão entre um egoísmo e outro. Embora haja de antemão o interesse próprio (Eigennutz), a malevolência se torna mais complexa porque há um choque impetuoso entre dois ou mais egoísmos. Tendo a aniquilação alheia como desejo principal, a malevolência é um produto da racionalidade em termos de planejamento de uma ação. Essa característica da malevolência, já indicada como motivação antimoral, pressupõe o ódio como motor da ação; a razão, por sua vez, serve como instrumento para o algoz por em prática suas pretensões contra a vítima. Assim, a maldade se apresenta em potencialidade e desenvolvimento, expressando a imutabilidade do caráter maldoso.

Por outro lado, a compaixão se revela como caridade desinteressada. O indivíduo compassivo reconhece no outro a sua própria essência, a ponto de estabelecer uma identidade com a dor alheia. Essa característica permitiria que se enxergasse além do Véu de Maia, restringindo ou eliminando o principium individuationis; dessa maneira se dissiparia a diferença entre o $e u$ e o $n \tilde{a} o e u$, restando somente a identificação do compassivo com o sofredor. No entanto, a compaixão não se baseia em conceitos abstratos; em verdade, ela se revelaria na participação imediata na dor do outro.

Nesses termos, o ponto de partida do místico na filosofia schopenhaueriana é identificado na caridade, que pressupõe o sentimento da compaixão. Desse modo, "podemos considerar as ações que lhe são concordes, por exemplo, a caridade, como início da mística", Esse é o ponto crucial da problemática apresentada, pois

\footnotetext{
${ }^{5}$ SCHOPENHAUER, A. Über die Grundlage der Moral-M/M, p. 121

${ }^{6} \mathrm{P} / \mathrm{P}$, cap. VIII, “Acerca da ética”, § 115, p. 201. 
Schopenhauer apresenta duas questões importantes: "Em que repousa a tão grande diferença no comportamento moral dos homens ${ }^{7}$ ?" "Pode ela [a ética] transformar um homem de coração duro num compassivo e, daí, num justo e caridoso ${ }^{8}$ ?". Partindo dessas indagações, o filósofo conclui que a diferença ética entre os caracteres seria inata e indelével, pois cada caráter carrega consigo no transcorrer de sua vida o selo impresso do determinismo. Nesse sentido, as três formas de motivação estão plenamente presentes e alicerçadas em relações diferentes. Assim, as ações se realizam em consonância com os motivos. Todavia, ainda que Schopenhauer realize uma singular análise das três motivações pela dimensão das ações humanas, emerge daí a possibilidade de uma redenção absoluta, ou de uma negação da Vontade não só livre de motivações, mas também de sofrimentos que a assolam constantemente. Sendo assim, as virtudes morais como a caridade e a justiça, quando são puras, nascem da própria vontade que transpassou o principium individuationis e se reconheceu como idêntica em todos os seus fenômenos. Estamos diante de um primeiro estímulo para a mortificação da vontade individual.

Em $O$ mundo como vontade e como representação, a Vontade era caracterizada por sua trajetória pelos diversos reinos da natureza. Atingindo o conhecimento de si via intuição estética ou intuição geral do mundo a Vontade alcançaria, inevitavelmente, uma clareza de consciência que viabilizaria a decisão pela própria afirmação ou negação. Neste último caso (negação da Vontade), embora haja comumente dois graus de intensidade ${ }^{9}$, lança-se a tese de que seria possível um terceiro grau, este marcado pela mística. Destarte, a liberdade consciente derivaria da supressão de todo o querer que conduz o homem às inclinações ilimitadas do egoísmo, conduzindo-o ao reconhecimento da Vontade para além do conhecimento turvado pelo Véu de Maia. Isso porque a exteriorização da liberdade consciente na esfera empírica acaba ficando comprometida. Por isso, deve-se questionar, a partir do que foi exposto, sobre o modo como aconteceria a exteriorização da liberdade consciente no fenômeno, seja no que tange à negação, seja no tangente à afirmação completa da Vontade de vida. Outro questionamento admissível é se haveria alguma possibilidade de o asceta ser motivado a fazer a manutenção dessa renúncia ao querer. Igualmente, pergunta-se se seria possível

\footnotetext{
${ }^{7}$ Fundamento, tr. bras., p. 190 [Grundlage, SW, III, p. 645]

${ }^{8}$ Idem, ibidem.

${ }^{9}$ Contemplação do belo e compaixão. Schopenhauer não deixou clara essa ideia (graus de negação). 
um direcionamento mais ousado sobre o problema da liberdade e sua dimensão puramente numênica. Considera-se aqui, que o exposto em uma nota de rodapé no suplemento 48 da obra principal de Schopenhauer ${ }^{10}$ seja um elemento desencadeador para uma análise sobre uma dita impossibilidade da liberdade consciente no fenômeno. Essa hipótese não só reconfigura a posição de Schopenhauer frente à problemática da liberdade, mas conduz a novos elementos que possibilitam compreender esse problema. A partir do momento em que há motivações (egoístas e maldosas), necessariamente não poderia haver liberdade. Nesse sentido, nem mesmo a compaixão como fenômeno espontâneo das ações humanas poderia ser considerado ato livre. A referida afirmação de que a compaixão não é um fenômeno que denote liberdade é ponto pacífico em Schopenhauer. O que não é pacífico é se a ascese pode ser considerada livre em termos de negação da vontade ou não. Resta averiguar se essas hipóteses tem viabilidade ou não.

Schopenhauer parece não desenvolver uma análise específica sobre uma possível liberdade pela via da compaixão, ao menos não há um capítulo exclusivo sobre isso em suas obras. Isso posto, é razoável considerar a lei de motivação como resposta para esse quadro; em outras palavras, a compaixão estaria submetida a um motivo. A esse respeito Cacciola comenta que:

$\mathrm{O}$ ato compassivo, apesar de estar fundamentado metafisicamente no reconhecimento da essência comum, manifesta-se ainda por meio de um motivo que é a representação do outro e do seu sofrimento. Neste sentido, como manifestação do caráter empírico, a ação compassiva não é livre, mas condicionada por um motivo ${ }^{11}$.

Embora sejam reconhecidos os méritos da análise de Schopenhauer sobre as motivações, é certo que o problema da liberdade exige um exame mais rigoroso. Destarte, na medida em que se percebem algumas possibilidades interpretativas que podem ter grandes consequências - como o caso do conquistador de mundos -, é necessário averiguar até que ponto o problema da liberdade permanece fiel aos pressupostos do livro IV de $O$ mundo como vontade e como representação.

\footnotetext{
${ }^{10}$ A referida nota de rodapé encontrar-se-á no final deste artigo.

${ }^{11}$ CACCIOLA, M. L., Schopenhauer e a questão do dogmatismo, p. 160. 
Para Schopenhauer, a realidade das ações humanas é compreendida como uma relação fundamental entre as motivações e a imutabilidade do caráter humano. A impossibilidade da liberdade no fenômeno deriva justamente dessa relação interna. Nesse sentido, a noção de negação da vontade, representaria a única possibilidade da liberdade consciente no fenômeno segundo Schopenhauer, uma vez que ocorreria uma ruptura decisiva dessa necessidade cujo sentido último é determinação dos motivos. Esses, por sua vez, não fariam mais efeito, justamente pela subtração do principium individuationis (tempo e espaço) ou, mais precisamente, pela visão plena através desse princípio, o que pressupõe o reconhecimento da unidade metafísica que se manifesta em cada fenômeno individual. Schopenhauer defende que no caso da negação ascética (para além da compaixão) os motivos passam a não mais fazer efeito e o que passa a ocorrer é uma espécie de conhecimento do todo da vida.

$\mathrm{Na}$ dissertação "O desafio da liberdade na filosofia de Schopenhauer",", procurou-se demonstrar que o problema da liberdade no âmbito negativo levaria Schopenhauer a postular outro modo em que poderia ocorrer a exteriorização da liberdade consciente na experiência empírica; trata-se da mais completa afirmação consciente da Vontade de vida ${ }^{13}$. Para tanto, teríamos que admitir a existência de um determinado indivíduo que reunisse todas as qualidades espirituais atribuídas ao asceta, com a diferença de que o mesmo continuasse a afirmar a vida com toda sua força. Uma passagem obscura expressa justamente essa análise:

\footnotetext{
${ }^{12}$ LIMA, F. C. O desafio da liberdade na filosofia de Schopenhauer. Curitiba: Dissertação de mestrado apresentada ao Departamento de Filosofia da PUCPR, 2011.

${ }^{13}$ Jair Barboza defende esse ponto de vista como se observa no excerto a seguir: Quando a Vontade chega ao conhecimento de si ela tem a possibilidade de afirmar-se ou negar-se - tema e título do último livro de O mundo... Chegando ao conhecimento de si, afirmação ou negação da Vontade de vida. De um "ponto de vista superior", "temos diante dos olhos não o que é individual, mas o todo". Deste ponto de vista, se uma pessoa, mesmo diante da morte e dos sofrimentos, ainda assim tivesse um poder de reflexão suficiente para afirmar a vida, "o seu retorno sempre novo", situar-se-ia na plena afirmação consciente da Vontade de vida. (Schopenhauer, 1988a, §54, p.372-4). "A Vontade afirma a si mesma significa: quando em sua objetidade, ou seja, no mundo e na vida, a própria essência lhe é dada plena e distintamente como representação, semelhante conhecimento não obsta de modo algum seu querer, mas exatamente esta vida assim conhecida é também enquanto tal desejada; se até então sem conhecimento, como ímpeto cego, doravante com conhecimento, consciente e deliberadamente" (ibidem, §54). A sexualidade, egoísmo, maldade, conservação do corpo entram na rubrica da afirmação inconsciente da vontade, mas o ponto de vista da "afirmação completa da Vontade de vida" é consciente, mediante a clareza de consciência, tratase de uma decisão a partir do autoconhecimento da Vontade. Nesse ponto ela transforma sua atividade em "conhecimento vivo". Um dos melhores exemplos dessa afirmação se encontra no caso do herói ou do conquistador. (Barboza, p. 263)
} 
Eis por que a maioria também exigirá que um homem, dotado de um elevadíssimo grau de maldade, apesar de ele ser encontrado em muitos outros homens, mas não acompanhados de qualidades parelhas com as dele, dentre as quais se pode mencionar a que o faz superior por uma força espiritual incomum, homem esse que é um conquistador de mundos, que infringiu sofrimentos inomináveis a milhões de outros a maioria também exigirá, ia dizer, que esse homem expie com igual medida de dor em algum momento e em algum lugar todo aquele sofrimento provocados nos outros, justamente porque desconhecem como torturador e torturado são em si unos; e a mesma Vontade pela qual o torturador existe e vive é também aquela que aparece no torturado, e justamente naquele atinge a manifestação mais distinta de sua essência. A Vontade sofre igualmente tanto no oprimido quanto no opressor, e em verdade neste último em graus ainda maiores, na proporção em que a consciência adquire maior clareza e distinção e a Vontade mais veemência ${ }^{14}$.

Quando a Vontade chega ao conhecimento de si, entra em cena a mais "completa afirmação da Vontade de vida”. Assim, poderíamos reconhecer a essência por intermédio de uma intuição geral do mundo, sem, no entanto, suprimir a fonte subjacente de sofrimentos, isto é, o próprio querer. Nesse sentido, afirma Schopenhauer: "esta vida assim conhecida é também enquanto tal desejada; se até então sem conhecimento, como ímpeto cego, doravante com conhecimento, consciente e deliberadamente". (Schopenhauer, 2005, p.369)

Tais considerações implicam na hipótese de uma interpretação diferente do conceito de afirmação da vontade sob duas maneiras opostas. De um lado, a completa afirmação da Vontade pode derivar do conhecimento consciente e perfeitamente adequado de sua própria essência acompanhado do querer - opção tomada via conhecimento do todo da vida que pressupõe a liberdade consciente. De outro lado, essa mesma afirmação da Vontade seria um incessante querer cego, uma liberdade inconsciente que reflete e manifesta a Vontade em mundo - Objektität des Willens. Sendo assim, assevera Schopenhauer:

Também já expusemos como alguém que se coloca com perfeita clareza de consciência no ponto de vista da decidida afirmação da vida encara a morte sem temor. [...] Porém, a maioria dos homens se coloca

\footnotetext{
${ }^{14}$ SCHOPENHAUER, A. MVR I, § 64, p. 457.
} 
Revista Voluntas: Estudos sobre Schopenhauer - Vol. 4, № 2 - $2^{\circ}$ semestre de 2013 - ISSN: 2179-3786 - pp. 53-68.

nesse ponto de vista sem nítida clareza de consciência e afirma a vida continuamente. ${ }^{15}$

A partir dessa afirmação é possível admitir que essa liberdade, cuja exteriorização é todo o fenômeno, possui o ápice de sua autoconsciência não apenas do ponto de vista cego, isto é, desconhecendo-se, mas também, conhecendo-se. Entretanto, considera-se neste artigo que o conhecimento do conquistador de mundos lhe permaneceria sempre um motivo, tanto no particular quanto no todo. Portanto, não haveria a possibilidade da exteriorização da liberdade consciente na esfera afirmativa, em função da influência das motivações.

Já no âmbito da negação da Vontade, ocorre um processo inverso, ou seja, o conhecimento do todo leva o querer à supressão, isso porque, nas palavras de Schopenhauer:

Os fenômenos particulares conhecidos não mais fazem efeito como motivos do querer, mas o conhecimento inteiro da essência íntima do mundo, que espelha a Vontade, e provém da apreensão das idéias, torna-se um quietivo da Vontade e, assim, a Vontade suprime a si mesma livremente ${ }^{16}$.

A intuição geral do mundo tem um papel fundamental para a concretização da negação da Vontade; do mesmo modo, uma ascese só pode existir diante de uma repulsão pela essência. Por meio do conhecimento do todo da vida, Schopenhauer chega ao grau máximo da negação da Vontade, a qual é um acontecimento raro e próprio do asceta. Assim como o conhecimento abstrato é nulo nesse processo, uma negação dos desejos da existência projeta um novo sentido, pois sua dinâmica pressupõe a constatação do sofrimento dos seres viventes e esse conhecimento serviria como um quietivo do querer.

Pensado desta forma, haveria aí uma contradição no fenômeno, pois como o corpo nunca é subtraído do domínio do princípio de razão, o querer se torna sempre latente, está lá, mas não pode condicionar o conhecimento justamente porque o intelecto não se submete ao principium individuationis; há, portanto, uma intuição que se eleva através do referido princípio. $\mathrm{O}$ asceta, assim, se associa à negação do próprio corpo,

\footnotetext{
${ }^{15}$ SCHOPENHAUER, A. MVR I, § 60, p. 425.

${ }^{16}$ SCHOPENHAUER, A. MVR I, § 54, p. 370 
mas a forma vigente do estado ascético tem de ser contínua. Por isso, o asceta se arremessa numa luta incessante contra as tentações da existência e dos interesses egoísticos, projetando, assim, a manutenção desse estado. Todavia, essa manutenção do ascetismo, na medida em que compreende a mortificação do corpo, direciona sempre a exercícios ascéticos, isto é, a uma busca contínua de tudo o que desagrada e repugna. $\mathrm{O}$ homem de disposição ascética delibera conscientemente o presente sempre para um futuro possível na esperança de prolongar o estado ascético.

Ao identificar que o elemento definidor do asceta é justamente o desejo consciente de intensificar o conhecimento do todo da vida ${ }^{17}$, parece razoável indagar se a ascese apresentaria em sua estrutura resquícios de motivações. Daí a necessidade de uma reconsideração do problema da liberdade que, como hipótese, necessitaria de uma averiguação.

De imediato, se apresentam duas considerações importantes:

a) como sugerido anteriormente, as motivações se tornariam nulas quando alcançado o grau máximo da renúncia ao querer viver, e, nesse caso, o conhecimento não estaria submetido ao principium individuationis - assim, o asceta ou o santo, que assim se comportam, tomam para si todos os sofrimentos do mundo;

b) o processo que conduz à negação da Vontade de vida é fruto imediato de uma ligação entre o interior e o exterior do homem (asceta), uma vez que nunca será possível compreender o menor de seus gestos sem a superação da influência das motivações pelo conhecimento do todo.

Partindo desta última reflexão, percebe-se não apenas a ideia da exteriorização da liberdade no fenômeno, mas também a necessidade de se considerar a liberdade atrelada ao conhecimento do todo como passagem curta, isto é, como uma manifestação imediata e repentina que repousa sobre a intuição, tal como indicado anteriormente.

${ }^{17} \mathrm{O}$ conhecimento do todo da vida é proveniente de uma intuição geral do mundo. Essa mesma problemática foi abordada por Vilmar Debona no livro intitulado Schopenhauer e as formas da razão: $O$ teórico, o prático e o ético-místico. Segundo Vilmar, pelo fato de haver essa manutenção do estado ascético haveria uma espécie de "razão ético-mística", o que ele chama de "terceira forma da razão" em Schopenhauer; justamente a "forma da razão" ou da "racionalidade" da Besonnenheit der Vernunft. Ainda de acordo com Debona, "a clarividência da razão apontada por Schopenhauer ao apontar o desejo do asceta em reconquistar a negação mediante o conhecimento do todo da vida, mesmo que seja de alguma forma interessada, pelo fato da própria intensificação desta negação ser um objetivo, mesmo assim esse anseio não pode ser o que, essencialmente, define e distingue a razão ético-mística. (Debona, 2010, p.128). 
Nesse sentido, é admissível levantar a hipótese de que, uma vez concretizada a viragem, aquela compreensão ou reconhecimento do todo não libertaria o asceta do peso das motivações. Assim, a liberdade estaria impossibilitada e a concepção schopenhaueriana de liberdade não só associada à negação total da Vontade, mas como ruptura das motivações mediante as condutas ascéticas estaria comprometida. ${ }^{18}$ Nesse sentido, não haveria uma liberdade no fenômeno, mas somente a constante luta do asceta contra as tendências afirmativas da vida, donde a necessidade de uma deliberação constante do homem pelo uso da razão se tornaria possível.

Embora a dimensão da razão se torne fundamental na manutenção desse estado ascético, como uma "condição de liberdade", o não desenvolvimento estendido dessa questão complica a compreensão da mesma em torno da Ética e da mística. No entanto, a força com que a "visão geral do todo da vida" se mostra como elemento sobre o qual a razão se edifica, na medida em que se trata de um "conhecimento que vai além do presente", legitima a análise aqui proposta. Ademais, à medida que é mantida a ascese, (quando entra em cena a Besonnenheit der Vernunft ${ }^{19}$ ), mesmo que após algumas ressalvas de Schopenhauer, parece inevitável indicarmos algumas contradições, o que justificaria por um lado, o papel determinante da razão no contexto Ético schopenhaueriano, pois, a negação total da Vontade pressupõe um movimento contínuo e doloroso, já que os graus de ascetismo mortificam a todo o momento a Vontade de vida. Por outro lado, mesmo a clarividência de razão não seria suficiente para interromper esse ciclo de uma motivação a outra, o que ainda deixaria o tema problemático.

Se admitido isso, ser-se-ia levada à conclusão de que a liberdade como negação da necessidade é apenas um atributo da essência universal, o que implicaria dizer que ou as motivações são constantes (tal como ocorre nos indivíduos egoístas, maldosos e compassivos) ou elas nunca fariam efeito no asceta, dada a constante pressão da negação do corpo; isso, levado ao extremo, acarretaria não só na liberdade consciente, mas também na subtração das motivações. Além do mais, se as motivações fossem

\footnotetext{
${ }^{18}$ Nesse sentido, teríamos que poder afirmar que aquele "quietivo" da vontade não faz qualquer sentido. No entanto, Schopenhauer acredita nele.

${ }^{19}$ Clarividência de razão. O ascetismo em sentido estrito configura uma negação total e duradoura da Vontade de vida. Nesse aspecto, a Besonnenheit der Vernunft pressupõe a manutenção desse estado.
} 
insuperáveis do ponto de vista ascético, de que serviria o conhecimento do todo da vida?

Eis aí um ponto bastante relevante, pois, uma vez que a compaixão não pode configurar uma liberdade porque está submetida a um motivo, é necessário averiguar se há alguma possibilidade para o asceta manter o reino da liberdade no fenômeno sem ser determinado pelas motivações. Em outras palavras, é necessário encontrar outro elemento que impossibilite a exteriorização da liberdade consciente no fenômeno em sua densidade própria, pois se as motivações suprimem a liberdade consciente no fenômeno, como compreender a liberdade relacionada a uma quarta motivação das ações humanas, considerando que a conduta de certos ascetas e santos é livre do domínio das motivações?

E aqui se trata simplesmente de reconhecer um ponto problemático na filosofia schopenhaueriana:

Pois exatamente aquilo que os místicos cristãos denominam efeito da GRAÇA e RENASCIMENTO é para nós a única e imediata exteriorização da LIBERDADE DA VONTADE. Esta só entra em cena quando Vontade, após alcançar o conhecimento de sua essência em si, obter dele um QUIETIVO, quando então é removido o efeito dos MOTIVOS, os quais residem em outro domínio de conhecimento cujos objetos são apenas fenômenos. Portanto a possibilidade de a liberdade exteriorizar-se a si mesma é a grande vantagem do homem, ausente no animal, porque a condição dela é a clarividência da razão, que o habilita a uma visão panorâmica do todo da vida, livre de impressão do presente. $\mathrm{O}$ animal está destituído de qualquer possibilidade de liberdade ${ }^{20}$.

O efeito da Besonnenheit der Vernunft é capaz de suprimir o motivo, a necessidade por excelência, por isso pode ser considerado um processo reflexivo da razão (então haveria liberdade). Entretanto, a linearidade dessas questões implica uma hipótese sobre a completa necessidade das ações, mesmo na reconquista ou manutenção progressiva dos atos ascéticos, tal como na castidade voluntária mediada pelo asceta que entra em conflito com o próprio corpo, na pobreza voluntária como possibilidade de se evitar novos desejos, no jejum e na autoflagelação como indícios da mortificação do corpo, e na aceitação plena da própria morte.

\footnotetext{
${ }^{20}$ SCHOPENHAUER, A. MVR I, § 70, p. 510.
} 
De fato, esse último grau representa o motor próprio da renúncia definitiva da vida, ou seja, o instante em que o "delgado laço" que liga os impulsos à vida é suprimido, e a razão como espectadora do conhecimento do todo da vida serve de instrumento libertador. Embora não tendo referido diretamente esse tema, em uma das notas de rodapé do suplemento 48, Schopenhauer aponta uma situação que corrobora a hipótese aqui levantada:

Cuando se admite, por el contrario, la práctica del ascetismo, hay que añadir a los tres móviles de la conducta humana que expuse en mi obra sobre el fundamento de la moral, y que son: $1^{\circ}$ nuestro propio bien; $2^{\circ}$ el mal de otro, y $3^{\circ}$ el bien de otro, un cuarto móvil, a saber: nuestro propio mal. Hago aquí esta observación incidental, solo para completar la serie sistemática. En mi Memoria, en que la cuestión AL concurso estaba planteada con arreglo al espíritu de la moral filosófica adoptada en los países protestantes de Europa, tuve que pasar en silencio este cuarto móvil ${ }^{21}$.

Em suma, trata-se de empreender aqui uma análise do alcance numênico da liberdade em Schopenhauer, uma vez que ele configura uma ambiguidade entre possiblidade e impossibilidade da mesma no âmbito fenomênico. Em outros termos, trata-se de analisar o limite entre o empírico e o inteligível sob o viés do alcance numênico da liberdade. Por isso embora o artigo possa denotar não só uma questão, mas também uma hipótese de defesa especificamente sobre a liberdade, ainda nos encontramos na ponta do iceberg de toda problemática, acredita-se que tal tese possibilite uma compreensão diferente de alguns elementos, além dos já referidos, e, sobretudo, do aspecto ético, na filosofia de Schopenhauer.

\section{Referências bibliográficas}

BARBOZA, Jair. A decifração do enigma do mundo. São Paulo: Moderna, 1997. Infinitude subjetiva e estética: natureza e arte em Schelling $e$ Schopenhauer. São Paulo: Unesp, 2005.

CACCIOLA, Maria Lúcia Mello e Oliveira. Schopenhauer e a questão do dogmatismo. São Paulo: Edusp, 1994.

\footnotetext{
${ }^{21}$ SCHOPENHAUER, A. MVR II, $\S 48$, p. 675.
} 
DEBONA, Vilmar. Schopenhauer e as formas da razão: o teórico, o prático e o éticomístico. São Paulo: Annablume, 2010.

REDYSON, Deyve. Arthur Schopenhauer no Brasil: em memória dos 150 anos da morte de Schopenhauer. João Pessoa: Ideia, 2010.

SCHOPENHAUER, Arthur. O mundo como vontade e como representação. Trad. de Jair. Barboza. São Paulo: Unesp, 2005.

SCHOPENHAUER, Arthur. El mundo como voluntad y representación (Tomo II). Madrid: Trotta, 1994.

. Sobre o fundamento da moral. Trad. de Maria. Lúcia M. O. Cacciola. São Paulo: Martins Fontes, 2001.

. Metafísica do amor, metafísica da morte. 2. ed. Trad. de Jair Barboza. São Paulo: Martins Fontes, 2004.

. O livre Arbítrio. São Paulo: Novo Brasil Editora, 1982.

Recebido: 20/05/14

Received: 05/20/14

Aprovado: 15/06/14

Approved: 06/15/14 